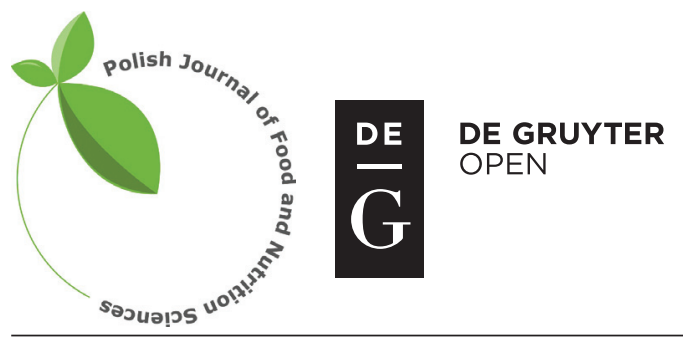

Pol. J. Food Nutr. Sci., 2017, Vol. 67, No. 1, pp. 41-48 DOI: $10.1515 /$ pjfns-2016-0003 http://journal.pan.olsztyn.pl

Original article

Section: Food Quality and Functionality

\title{
Characterization of Probiotic Abilities of Lactobacilli Isolated from Iranian Koozeh Traditional Cheese
}

\author{
Mahmoud Tavakoli ${ }^{1}$,Zohreh Hamidi-Esfahani ${ }^{1 *}$, Mohammad Amin \\ Hejazi $^{2}$, Mohammad Hossein Azizi ${ }^{1}$, Soleiman Abbasi ${ }^{1}$
}

\author{
${ }^{1}$ Department of Food Science and Technology, Faculty of Agriculture, \\ Tarbiat Modares University, P.O. Box 14115-336, Tehran, Iran \\ ${ }^{2}$ Department of Food Biotechnology, Branch for Northwest \& West region, Agricultural Biotechnology \\ Research Institute of Iran, Agricultural Research, Education and Extension Organization (AREEO), Tabriz, Iran
}

Key words: probiotic cheese, lactic acid bacteria (LAB), antibacterial, antibiotic resistance, gastric resistance, cell surface hydrophobicity

Eight lactic isolates including Lactobacillus plantarum (MT.ZH193, MT.ZH293, MT.ZH393 and MT.ZH593), L. casei (MT.ZH493), L. pentosus (MT.ZH693), and L. fermentum (MT.ZH893 and MT.ZH993) were identified from an Iranian traditional cheese "Koozeh Paneer" using the morphological, phenotypical, biochemical and molecular characterization and then their probiotic characteristics were compared. Results showed that the lactic isolates of L. plantarum (MT.ZH293) and L. fermentum (MT.ZH893 and MT.ZH993) were resistant to all the used bile salts up to concentrations of 0.3 to 2.0\%. All the strains showed low sensitivity to the presence of conjugated bile salts. L. plantarum MT.ZH293 exhibited the highest enzymatic activity of $\beta$-galactosidase and survival rate in a simulated stomach duodenum passage. L. casei MT.ZH493 generated the highest amount of hydrogen peroxide, followed by L. fermentum MT.ZH993 and L. plantarum MT.ZH593. Although the most selected LAB isolates had a moderate cell surface hydrophobicity, L. plantarum MT. ZH593 expressed the highest cell surface hydrophobicity. L. fermentum MT.ZH893 had strong resistance to all the antibiotics tested such as amoxicillin, ceftriaxon, chloramphenicol, erythromycin, gentamycin, streptomycin, tetracycline and vancomycin. Five lactic strains of $L$. plantarum (MT.ZH193, MT.ZH393 and MT.ZH593) and L. fermentum (MT.ZH893 and MT.ZH993) inhibited the growth of the tested foodborne pathogens including Escherichia coli PTCC5052, Salmonella enterica, Enetrococcus hirea, Staphylococcus aureus and Pseudomonas aeruginosa.

\section{INTRODUCTION}

Probiotics are defined as "living microorganisms" because they have numerous health advantages such as enhanced immune response, alleviation of symptoms of lactose intolerance, diarrhea treatment, serum cholesterol reduction, vitamin synthesis and anti-carcinogenic and anti-microbial activities [Libudzisz, 2006; Shah, 2007]. In recent years, probiotic food products are the main sectors of the global trade market and are possible to grow at a compound annual growth rate of $6.8 \%$ from 2013 to 2018 and predictable to reach US\$ 37.9 billion in 2018 [Sharma et al., 2014]. Meanwhile, probiotic dairy products constitute one of the most developed segments and represent a major branch of the functional foods industry [Saad et al., 2013]. In comparison to yoghurt, cheese is an interesting food-based delivery vehicle of probiotics to the gastro-intestinal tract because of a higher $\mathrm{pH}$, a higher fat content and a higher solid consistency [Özer et al., 2008]. Some researchers evaluated a variety of food-grade lactic acid bacteria (LAB) isolated from the Italian Castelmagno PDO cheese [Belviso et al., 2009], Italian and Argentinean cheeses [Zago et al., 2011] for their probiotic potential and used

\footnotetext{
* Corresponding Author:

E-mail: hamidy_z@modares.ac.ir (Prof. Z. Hamidi-Esfahani)
}

them as adjunct cultures in different types of food products or in therapeutic preparations. The lactobacilli isolated from dairy products especially cheese have shown a long history of safe use as these microorganisms are widely applied as starter cultures in the development of novel fermented milk or meat products, alcoholic beverages and sourdough [Salari et al., 2015; Shokoohi et al., 2015; Torkamani et al., 2015].

Overall, a probiotic lactobacillus should be able to survive (at least $10^{6} \mathrm{CFU} / \mathrm{mL}$ ) during the food processing steps and the product shelf-life, and should be also desirable to offer a contribution to the sensory attributes of the final product [dos Santos et al., 2015]. The new probiotic strains must also be resistant to the adverse conditions of the human gastrointestinal tract that have physiological properties compatible with probiotic potential and technological relevance for use in food products [Kirmaci, 2016; El-Shafei et al., 2008; Makinen et al., 2012]. Therefore, evaluation of the functional properties in vitro and in vivo not only must consider in selection of suitable probiotic bacteria, but also their technological ones, framing the microorganism within the industrial reality [Ferrando et al., 2015]. In this investigation, some characteristics related to probiotic potential, functionality and technological applications of LAB strains isolated from artisanal Koozeh produced from ewe's or goat's milk in the northern region of Iran were critically studied. 


\section{MATERIALS AND METHODS}

\section{Chemicals, reagents and culture medium}

Sodium salts of glycocholic acid (GC), glycodeoxycholic acid (GDC), taurocholic acid (TC), and taurodeoxycholic acid (TDC) were purchased from Merck Chemical Co. (Darmstadt, Germany). O-nitrophenyl $\beta$-galactopyranoside (ONPG) was obtained from Oakville (ON, Canada). Peroxidase, o-dianisidine, bile salts, ethidium bromide, agarose gel and RNase were supplied by Sigma-Aldrich Chemical Co. (St. Louis, MO, USA). Pepsin, pancreatin, glycerol, $\mathrm{NaCl}$, sodium phosphate buffer, sodium thioglycolate and hydrocarbon of hexadecane were provided by Merck Chemical Co. (Darmstadt, Germany). Amoxicillin, ceftriaxon, chloramphenicol, erythromycin, gentamicin, streptomycin, tetracycline and vancomycin were provided by the Razi Vaccine and Serum Research Institute (Karaj, Iran). deMan, Rogosa and Sharpe (MRS) broth and brain heart infusion soft agar (BHI agar) were respectively provided by Merck Chemical Co. (Darmstadt, Germany), and Sigma-Aldrich Chemical Co. (St. Louis, MO, USA).

\section{Sample collection}

In this study, a total of five samples of Koozeh cheese were randomly collected from the rural areas of Mazandaran province including Babol $\left(\mathrm{C}_{\mathrm{b}}\right)$, Cherat $\left(\mathrm{C}_{\mathrm{ch}}\right)$, Alasht $\left(\mathrm{C}_{\mathrm{a}}\right)$, Shirgah $\left(\mathrm{C}_{\mathrm{sh}}\right)$, and Firouzkouh $\left(\mathrm{C}_{\mathrm{f}}\right)$. The main production steps of this traditional cheese include: coagulation of ewe's or goat's milk with lamb or commercial calf rennet at $33-34^{\circ} \mathrm{C}$ (45-60 min), curd mashing and putting on a cloth, hanging it for whey drainage (14-15 h), curd transferring to a large cloth bag and adding dry salt onto the surface, the curd, grinding and putting it into a pot and finally ripening buried in the underground at the shade for 2-3 months. After the testing of the $\mathrm{pH}$ value of pre-mixed cheese samples, they were transferred to the laboratory under refrigeration at $-80^{\circ} \mathrm{C}$ until the time of isolation and tests.

\section{Isolation of the LAB from Koozeh cheese}

The sample $(30 \mathrm{~g}$ ) was inoculated into $300 \mathrm{~mL}$ of MRS broth, centrifuged and then anaerobically incubated at $37^{\circ} \mathrm{C}$ for $24 \mathrm{~h}$. In next step, $25 \mathrm{~mL}$ of the broth was centrifuged at $1000 \times g$ for $20 \mathrm{~min}$ and the pellet was re-suspended into $10 \mathrm{~mL}$ of phosphate-buffered saline (PBS) adjusted to $\mathrm{pH} 2.5$ with $5 \mathrm{~mol} / \mathrm{L} \mathrm{HCl}$, and incubated at $37^{\circ} \mathrm{C}$ for $2 \mathrm{~h}$. The medium was centrifuged at $5000 \times g$ for $25 \mathrm{~min}$, pellet was re-suspended in a Ringer's solution and plated on an MRS agar plate [Pennacchia et al., 2004]. The colonies of lactobacilli were screened on MRS agar containing nystatin to avoid initial time-consuming isolation steps and yeast interference [Gardiner et al., 2004]. Plates were incubated at $37^{\circ} \mathrm{C}$ for $24-48 \mathrm{~h}$ under anaerobic conditions. Representative colonies of all morphologies were randomly taken and purified on the same media by subculturing. Gram-positive, catalase-negative isolates after gram staining and catalase reaction were considered as presumptive $\mathrm{LAB}$, which were stored in $15 \%$ glycerol at $-80^{\circ} \mathrm{C}$.

\section{PCR amplification of the $16 S$ ribosomal DNA}

DNA of the lactobacilli cells was extracted with chloroform-isoamyl alcohol (24:1). Samples were also dipped in liq- uid nitrogen, and $0.1 \mathrm{mg} / \mathrm{mL}$ RNase was added at the end of the procedure. The DNA was amplified by PCR in a Perkin-Elmer thermal cycler (Applied Biosystems ${ }^{\circledR}$, model 9700, USA) using the primer sequences which were as follows: forward primer, 5'-AGAGTTTGATCCTGGCTCAG-3' and reverse primer, 5'-GTCTCAGTCCCAATGTGGCC-3' (Biotez, Berlin, Germany). The primers were used to amplify a $350 \mathrm{bp}$ region of the $16 \mathrm{~S}$ rRNA gene. PCR amplifications were performed in $20 \mu \mathrm{L}$ volumes with $0.5 \mu \mathrm{mol} / \mathrm{L}$ of each primer, 2.5 units $/ 100 \mu \mathrm{L}$ of AmpliTaq DNA polymerase, $1.5 \mathrm{mmol} / \mathrm{L} \mathrm{MgCl}_{2}, 20 \mathrm{ng}$ of total DNA, and $200 \mu \mathrm{mol} / \mathrm{L}$ of each dNTP. The thermal cycler was programmed as follows: 10 min at $94^{\circ} \mathrm{C} ; 25$ cycles of $1 \mathrm{~min}$ at $94^{\circ} \mathrm{C}, 2 \mathrm{~min}$ at $61^{\circ} \mathrm{C}$, and $2 \mathrm{~min}$ at $72^{\circ} \mathrm{C}$; and $5 \mathrm{~min}$ at $72^{\circ} \mathrm{C}$. The amplification products were analyzed by electrophoresis on a $1 \%(\mathrm{w} / \mathrm{v})$ agarose gel and visualized after staining with ethidium bromide $(0.5 \mu \mathrm{g} / \mathrm{mL})$. The $16 \mathrm{~S}$ rRNA gene sequence was compared with sequences available in the nucleotide database using the BLAST algorithm at the NCBI server.

\section{Measurement of bile tolerance}

The method of Leite et al. [2015] using a plate assay was applied to determine the ability of the LAB strains to grow in the presence of bile salts including sodium glycocholate (GC), sodium glycodeoxycholate (GDC), sodium taurocholate (TC) and sodium taurodeoxycholate (TDC). For this experiment, individual colonies growing in MRS agar plates were suspended in $2-5 \mathrm{~mL}$ of sterile saline solution $0.85 \%$ at a density corresponding to McFarland standard no. 1 . In the next step, aliquots of the suspensions $(10 \mu \mathrm{L})$ were spotted onto bile-containing $0.3,0.5,1.0$, and $2.0 \%$ (w/v) agar plates. The plates were incubated at $37^{\circ} \mathrm{C}$ under anaerobic conditions and growth was recorded after 24 to $48 \mathrm{~h}$. Positive control was a plate without bile salts. The experiments were performed in duplicate.

\section{Bile salts deconjugation assay}

Bile salts deconjugation was measured based on the procedure of Vinderola \& Reinheimer [2003]. In brief, after preparing sterile plates of bile salt by adding $0.5 \%(\mathrm{w} / \mathrm{v})$ of sodium salts of GC, GDC, TC and TDC to MRS agar, the strains were immediately streaked on the media and anaerobically incubated at $37^{\circ} \mathrm{C}$ for $72 \mathrm{~h}$. A positive result was the presence of precipitated bile salts around colonies (opaque halo).

\section{Tolerance to simulated gastric juice}

Pellets of the bacterial cells cultivated overnight were obtained using centrifugation at $5000 \times \mathrm{g}$ for $10 \mathrm{~min}$, washed thoroughly with sodium phosphate buffer ( $0.1 \mathrm{~mol} / \mathrm{L}, \mathrm{pH} 7.0)$, and re-suspended in a sterile electrolyte solution. For the next step, the suspension was directly mixed to the same volume of gastric solution (w/v) including $0.6 \%$ pepsin and $1 \% \mathrm{NaCl}$ and then incubated in a $37^{\circ} \mathrm{C}$ water-bath with gentle agitation for $1.5 \mathrm{~h}$ to acidify slowly from $\mathrm{pH} 5.0$ to 2.2 . The cells count on MRS agar at times of 0,30,60, 70, 80, and 90 min was carried out [Blanquet et al., 2004]. An aliquot of each cell suspension was taken after $90 \mathrm{~min}$, pelleted by centrifugation under the same conditions and the cells were re-suspended in sodium phosphate buffer $(0.1 \mathrm{~mol} / \mathrm{L}, \mathrm{pH} 8.0)$ containing $0.3 \%$ bile 
and $0.1 \%$ pancreatin and kept at $34^{\circ} \mathrm{C}$ for $1 \mathrm{~h}$ and followed by counting [Zago et al., 2011]. Washed cells re-suspended in sodium phosphate buffer and subjected to the same conditions as treated samples were used as controls. Survival rate was determined as percentage of the $\mathrm{CFU} / \mathrm{mL}$ after $30,60,70$, 80, $90 \mathrm{~min}$ and $150 \mathrm{~min}$ compared to the $\mathrm{CFU} / \mathrm{mL}$ at time 0 .

\section{Determination of $\boldsymbol{\beta}$-galactosidase activity}

$\beta$-Galactosidase activity of the screened lactobacilli was evaluated using sterile filter paper disks impregnated with ONPG based on the method described by dos Santos et al. [2015] with minor modifications. In brief, the bacterial isolates were overnight cultivated on plates of MRS broth and anaerobically incubated at $37^{\circ} \mathrm{C}$ for $48 \mathrm{~h}$. A colony of each culture was picked up, emulsified in a tube containing ONPG disk added with $0.1 \mathrm{~mL}$ of sterile $0.85 \% \mathrm{NaCl}$ solution, incubated at $35^{\circ} \mathrm{C}$, and visualized in a $1 \mathrm{~h}$-interval during a 6 h-time. The release of $O$-nitrophenol as a yellow chromogenic compound showed a positive result for $\beta$-galactosidase production.

\section{Cell surface hydrophobicity assay}

The adhesion ability of selected LAB to hexadecane hydrocarbon was determined in vitro as previously described by Rosenberg et al. [1980]. Percent decrease in absorbance of the aqueous phase as compared to that of original cell suspension was considered as the fraction of adherent cells. The percent adhesion or the cell surface hydrophobicity (CSH) was determined using the following equation (Eq. 1):

$$
\operatorname{CSH}(\%)=100 \times\left(-1 \frac{D O_{b}}{D O_{a}}\right)
$$

where $D O_{a}$ and $D O_{b}$ respectively are the absorbance (at $400 \mathrm{~nm}$ ) before and after mixing with hydrocarbon solvents.

\section{Determination of susceptibility to antibiotics}

Susceptibility of the selected LAB strains to the different antibiotics was evaluated using antibiotics susceptibility test discs (Oxoid, Basingstoke, UK). The LAB strains were cultivated in MRS broth and incubated at $37^{\circ} \mathrm{C}$ for $48 \mathrm{~h}$ to reach $10^{6}-10^{7} \mathrm{CFU} / \mathrm{mL}$. The LAB strains were inoculated onto surface of MRS agar medium. The disks were then used on MRS agar plates and incubated at $37^{\circ} \mathrm{C}$ for $24 \mathrm{~h}$. Levels of the applied antibiotics including amoxicillin, ceftriaxon, chloramphenicol, erythromycin, gentamycin, streptomycin, tetracycline and vancomycin were 25, 30, 30, 15, 10, 10, 30 and $30 \mu \mathrm{g}$ per disk, respectively [dos Santos et al., 2015]. Inhibition zone diameters in millimeter $(\mathrm{mm})$ were measured to assess the strain sensitivity.

\section{Ability of hydrogen peroxide production}

A modified procedure of Villegas \& Gilliland [1998] was used to assess hydrogen peroxide (HP) production in the medium of tryptic soy broth-yeast extract (TSB-YE) after $24 \mathrm{~h}$ incubation at $30^{\circ} \mathrm{C}$. To this end, $1.0 \mathrm{~mL}$ of peroxidase aqueous solution $(0.1 \% \mathrm{w} / \mathrm{v})$, and $1.0 \mathrm{~mL}$ of o-dianisidine aqueous solution $(1.0 \% \mathrm{w} / \mathrm{v})$ were mixed into a test tube and subsequently $5.0 \mathrm{~mL}$ of a cell-free supernatant were added and in- cubated at $37^{\circ} \mathrm{C}$ for $10 \mathrm{~min}$. Finally, the chemical reaction was stopped by adding $0.2 \mathrm{~mL}$ of $5 \mathrm{~mol} / \mathrm{L} \mathrm{HCl}$ and absorbance of the sample was measured at $400 \mathrm{~nm}$ using an UV-visible spectrophotometer (U-5100 model, Hitachi, Japan). A blank sample was made with $5.0 \mathrm{~mL}$ of TSB-YE instead of the supernatant.

\section{Antimicrobial activity}

An agar spot test according to Ripamonti et al. [2011] was applied to find the ability of selected LAB strains to inhibit a group of foodborne pathogens such as Escherichia coli, Salmonella enterica, Enterococcus hirea, Staphylococcus aureus and Pseudomonas aeruginosa. The mentioned strains originated from the Agricultural Biotechnology Research Institute of Iran (Karaj, Iran). The test cultures $(2 \mu \mathrm{L})$ were overnight spotted on the surface of the modified MRS agar (without ammonium citrate and sodium acetate), anaerobically incubated at $30^{\circ} \mathrm{C}$ for $24 \mathrm{~h}$, and then the cells were inactivated with chloroform for $30 \mathrm{~min}$. BHI agar (10 mL, 0.7\%) as an enriched non-selective medium was mixed with a $100-\mu \mathrm{L}$ volume of an overnight culture of each indicator, poured onto MRS agar plates and aerobically incubated at $37^{\circ} \mathrm{C}$ for 24 h. L. acidophilus ATCC 4356 was applied as a negative control. Inhibition but no clear-cut halo or a halo $<1 \mathrm{~mm}$ was recorded as $( \pm)$, a clear zone of growth inhibition around spots $>1 \mathrm{~mm}$ was scored as positive $(+)$, no inhibition was recorded as negative $(-)$, and an inhibition zone between 2 and $5 \mathrm{~mm}$ surrounding the colony was exhibited as $(++)$.

\section{Statistical analysis}

Results are expressed as the mean and standard deviation (SD) with triplicate determinations. Analysis of variance (ANOVA) with the Duncan test was carried out to verify if there is a significant difference among different LAB strains in the investigated traits. Data were statistically analyzed at the significance level of $\mathrm{P}<0.05$.

\section{RESULTS AND DISCUSSION}

Three hundred bacterial isolates were initially obtained from five cheese samples collected from Mazandaran province (Iran). The different isolates on the basis of characteristics of colony morphology (shape, surface and color), cell morphology (shape and size), phenotypic and lactobacillus specific biochemical features were investigated. Eight bacterial isolates were considered to belong to the genus lactobacillus based on morphological, cultural and biochemical characteristics [Jayne-Williams, 1976]. Representative 16S rDNA amplicons of each of the different profiles were selected for sequencing. Sequence comparisons in terms of the molecular identification showed a homology higher than $95 \%$ to four different LAB species [Sharpe et al., 1979]. There, the eight isolates were identified as follows: L. plantarum (MT.ZH193, MT.ZH293, MT.ZH393 and MT.ZH593), L. casei (MT. ZH493), L. pentosus (MT.ZH693), and L. fermentum (MT. ZH893 and MT.ZH993). Thus, these isolates were further characterized for the probiotic potential and the results are discussed in the following sections. 
TABLE 1. Chosen probiotic properties of LAB isolated from Koozeh cheese.

\begin{tabular}{|c|c|c|c|c|c|c|c|c|}
\hline \multirow[b]{2}{*}{ Probiotic properties } & \multicolumn{8}{|c|}{ Strains } \\
\hline & $\begin{array}{l}\text { L. plantarum } \\
\text { MT.ZH193 }\end{array}$ & $\begin{array}{l}\text { L. plantarum } \\
\text { MT.ZH293 }\end{array}$ & $\begin{array}{l}\text { L. plantarum } \\
\text { MT.ZH393 }\end{array}$ & $\begin{array}{l}\text { L. plantarum } \\
\text { MT.ZH593 }\end{array}$ & $\begin{array}{c}\text { L. casei } \\
\text { MT.ZH493 }\end{array}$ & $\begin{array}{l}\text { L. pentosus } \\
\text { MT.ZH693 }\end{array}$ & \begin{tabular}{|c|} 
L. fermentum \\
MT.ZH893
\end{tabular} & $\begin{array}{l}\text { L. fermentum } \\
\text { MT.ZH993 }\end{array}$ \\
\hline \multicolumn{9}{|l|}{ Bile tolerance assay* } \\
\hline Growth plate $-0.3 \%$ bile & + & + & + & + & + & + & + & + \\
\hline Growth plate $-0.5 \%$ bile & + & + & + & + & + & + & + & + \\
\hline Growth plate $-1.0 \%$ bile & - & + & + & + & + & - & + & + \\
\hline Growth plate $-2.0 \%$ bile & - & + & - & - & - & - & + & + \\
\hline Lag time (h), $0.3 \%$ bile & 1.50 & 0.38 & 1.15 & 0.90 & 0.60 & 2.35 & 0.11 & 0.50 \\
\hline \multicolumn{9}{|l|}{$\begin{array}{l}\text { Deconjugation } \\
\text { of bile salts*** }\end{array}$} \\
\hline $\begin{array}{l}\text { Sodium glycocholate } \\
\text { (GC) }\end{array}$ & $\mathrm{g}$ & g & g & $\mathrm{g}$ & $\mathrm{g}$ & $\mathrm{g}$ & g & g \\
\hline $\begin{array}{l}\text { Sodium } \\
\text { glycodeoxycholate } \\
\text { (GDC) }\end{array}$ & - & + & - & g & g & - & g & wg \\
\hline $\begin{array}{l}\text { Sodium taurocholate } \\
\text { (TC) }\end{array}$ & $\mathrm{g}$ & + & + & + & + & g & + & ++ \\
\hline $\begin{array}{l}\text { Sodium } \\
\text { taurodeoxycholate } \\
\text { (TDC) }\end{array}$ & + & + & + & g & + & g & ++ & + \\
\hline $\begin{array}{l}\beta \text {-Galactosidase } \\
\text { activity**** }\end{array}$ & Y & YY & Y & Y & Y & $\mathrm{NC}$ & Y & Y \\
\hline $\mathrm{CSH}(\%)^{* * * * * * *}$ & $24.92 \pm 2.11^{\mathrm{d}}$ & $22.61 \pm 3.07^{\mathrm{d}}$ & $38.79 \pm 1.21^{\mathrm{c}}$ & $62.54 \pm 0.78^{\mathrm{a}}$ & $14.56 \pm 0.14^{\mathrm{e}}$ & $41.61 \pm 0.05^{\mathrm{bc}}$ & $58.39 \pm 0.41^{\mathrm{a}}$ & $47.20 \pm 0.22^{b}$ \\
\hline $\begin{array}{l}\mathrm{H}_{2} \mathrm{O}_{2} \text { production } \\
(\mu \mathrm{g} / \mathrm{mL})^{* * * * * *}\end{array}$ & $5.12 \pm 0.07^{c}$ & $4.41 \pm 0.10^{\mathrm{d}}$ & $0.00 \pm 0.00^{\mathrm{e}}$ & $6.95 \pm 0.03^{\mathrm{a}}$ & $7.12 \pm 0.16^{\mathrm{a}}$ & $6.26 \pm 0.09^{b}$ & $6.06 \pm 0.04^{\mathrm{b}}$ & $7.02 \pm 0.08^{\mathrm{a}}$ \\
\hline
\end{tabular}

$*_{-}-=$no growth $+=$positive growth; ${ }^{*} *_{-}=$no growth; $\mathrm{wg}=$ weak growth; $\mathrm{g}=$ growth $;+=$ growth and bile salt deconjugation; $++=$ growth and strong bile salt deconjugation; ${ }^{* * *} \mathrm{YY}=$ strong yellow color; $\mathrm{Y}=$ yellow color; $\mathrm{NC}=$ no color change; $* * * *$ Values in the same columns followed by different letters $(\mathrm{a}-\mathrm{e})$ are significantly different $(\mathrm{p}<0.05)$, according to Duncan's multiple range test.

\section{Bile resistance}

Among eighty investigated LAB isolates, eight isolates showed tolerance to $\mathrm{pH} 3.0$ during 3-h incubation. These eight selected isolates were tested to determine the resistance to the different bile concentrations ranging from 0.3 to $2.0 \%$. Table 1 represents a lag time between 0.11 and $2.35 \mathrm{~h}$ for eight lactobacilli isolates. As a result of the bile tolerance assay, eight isolates grew in 0.3 and $0.5 \%, 6$ isolates in $1.0 \%$ and 3 isolates in $2.0 \%$. Three isolates of L. plantarum (MT. ZH293), and L. fermentum (MT.ZH893 and MT.ZH993) were resistant to all the studied bile concentrations. However, Pinto et al. [2006] applied bile concentrations ranging from 0.15 to $0.5 \%$, whereas Mathara et al. [2008] established a limit of $0.3 \%$ bile to select strains considered to have good resistance. Therefore, the lactobacilli isolated from Koozeh cheese were able to grow in very high concentrations of bile salts. Similar findings have been earlier reported for LAB strains obtained from different environments [Leite et al., 2015; Vinderola et al., 2008; Zago et al., 2011]. Evaluating the ability of potentially probiotic bacteria to resist a high content of bile salts is very important in their technological and physiological applications because this character not only is a selection criterion, but also because lactobacilli have been revealed to exhibit a strain variation in their tolerance to bile salts [Xanthopoulos et al., 2000].

\section{Bile salts deconjugation}

The results of probiotic characterization of the selected lactobacilli isolates in the presence of TC, TDC, GC and GDC have been shown in Table 1. All the isolated strains grew in the presence of GC. Regarding individual bile salts, GDC completely inhibited the growth of two strains of $L$. plantarum (MT.ZH193 and MT.ZH393) and L. pentosus (MT. ZH693). L. plantarum (MT.ZH293) was the only selected isolate able to deconjugate GDC (Table 1). Most LAB isolates had a potential to hydrolyze TC and TDC. However, both L. fermentum strains of MT.ZH993 and MT.ZH893 strongly hydrolyzed TC and TDC, respectively (Table 1). Bile salt deconjugation as an interesting property has a key role in reducing serum cholesterol, maintaining the gut equilibrium and the production and development of a detergent shock protein that enables lactobacilli to survive exposure to bile [Vinderola et al., 2008]. While many LABs in earlier studies were usually inhibited by bile salts, the selected lactobacilli isolates from Koozeh cheese proved to be resistant to their toxicity since these microorganisms were capable to grow in the medium comprising $0.5 \%$ of any of the bile salts tested. However, similarly to our results, Brashears et al. [1998] reported strains of $L$. casei and L. acidophilus were able to deconjugate sodium-TC. Table 1 shows that some strains were able to grow in the presence of conjugated bile salts while they were not able to deconjugate them. This fact can be attributed 


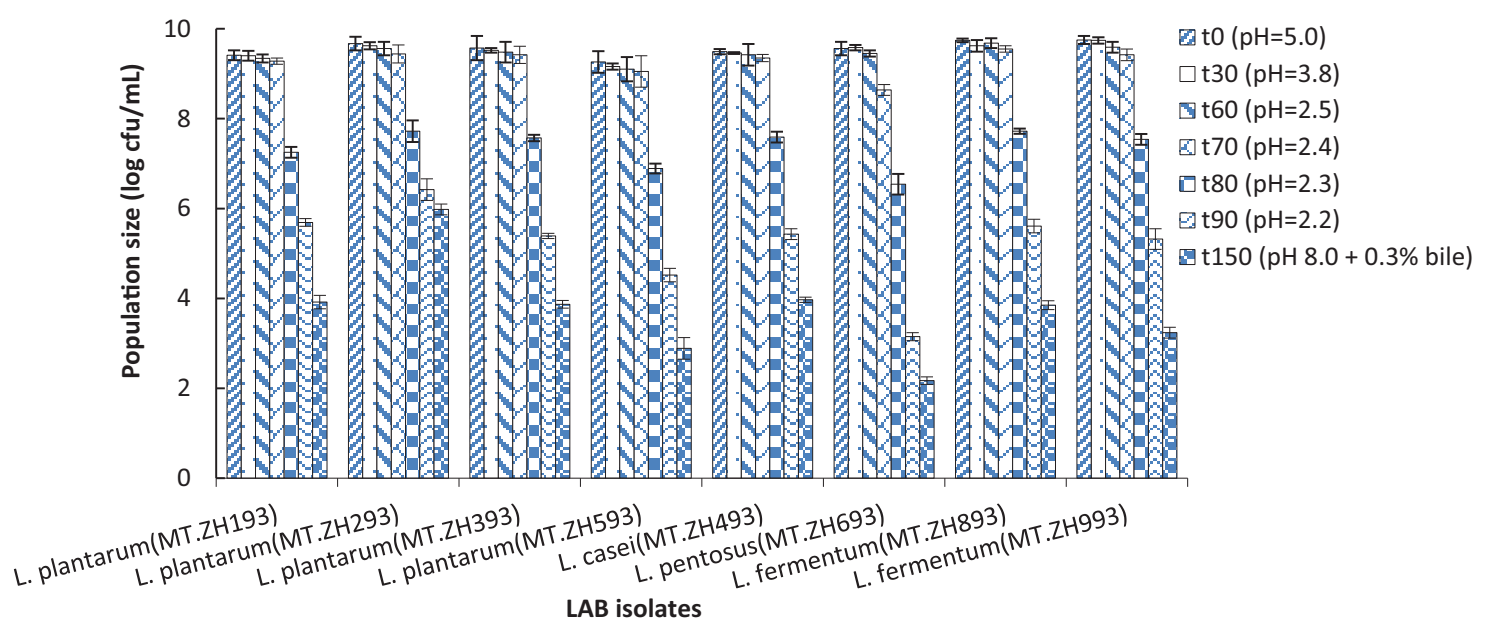

FIGURE 1. Effect of simulated gastric juice on the selected isolates of LAB from Koozeh cheese during $2.5 \mathrm{~h}$-gastric transit $\mathrm{t}_{0}: \mathrm{t}=0 \mathrm{~min} ; \mathrm{t}_{30}: \mathrm{t}=30 \mathrm{~min}$; $\mathrm{t}_{60}: \mathrm{t}=60 \min ; \mathrm{t}_{70}: \mathrm{t}=70 \min ; \mathrm{t}_{80}: \mathrm{t}=80 \mathrm{~min} ; \mathrm{t}_{90}: \mathrm{t}=90 \min ; \mathrm{t}_{150}: \mathrm{t}=150 \mathrm{~min}$.

to the ability of isolates to express bile salt hydrolase (BSH) activity which is not related to their ability to resist the toxicity of conjugated bile salts [Moser \& Savage, 2001].

\section{Tolerance to simulated gastric juice}

Figure 1 illustrates the resistance of lactobacilli isolates from Koozeh cheese under simulated gastric juice conditions. As depicted in this figure, there is no significant difference in tolerance to simulated gastric juice within the first $70 \mathrm{~min}$ between the various isolates when the $\mathrm{pH}$ decreases from 5.0 to 2.4. A drastic decrease was found in population size of the LAB isolates by increasing $\mathrm{pH}$ from 2.3 to 8.0 as the cell populations reached lower than $4.0 \log \mathrm{CFU} / \mathrm{mL}$ (Figure 1). Only two isolates of L. plantarum (MT.ZH593) and L. pentosus (MT.ZH693) after $90 \mathrm{~min}$ at $\mathrm{pH} 2.2$ had a cell count lower than $5.0 \log \mathrm{CFU} / \mathrm{mL}$. However, L. plantarum (MT.ZH293) had the highest survival at $\mathrm{pH} 2.2$ with $6.42 \log \mathrm{CFU} / \mathrm{mL}$ (Figure 1; P < 0.05). Generally, L. plantarum (MT.ZH293) was able to better survive the simulated stomach duodenum passage as re-suspended in a solution at $\mathrm{pH} 8.0$ with $0.3 \%$ bile and $0.1 \%$ pancreatin for a further $60 \mathrm{~min}$ at $37^{\circ} \mathrm{C}$, its survival rate insignificantly varied and the cell counts stayed at about $6 \log$ CFU/mL (P>0.05). Prasad et al. [1998] reported only a few strains of lactobacilli and bifidobacteria were intrinsically able to resist satisfactorily to gastric transit. A similar strain-dependent tolerance to a simulated stomach duodenum-passage was also found in L. plantarum strains isolated from Italian and Argentinean cheeses [Zago et al., 2011].

\section{$\boldsymbol{\beta}$-Galactosidase activity}

Table 1 reveals that only L. pentosus MT.ZH693 did not produce an intense yellow color, therefor it does not have any $\beta$-galactosidase activity. However, L. plantarum MT.ZH293 exhibited an intense-yellow color which was showing high enzymatic activity of $\beta$-galactosidase. A similar degradation of lactose by L. plantarum and L. acidipiscis isolated from Chiapas cheese was previously reported by Zago et al. [2011]. Since source of these LABs was a dairy product "Koozeh cheese", the presence of $\beta$-galactosidase is not surprising. Nevertheless, this desirable character provides them as ideal starter cultures in the dairy industry to develop formulations with excellent organoleptic and physicochemical attributes. $\beta$-Galactosidase is a key enzyme in hydrolyzing lactose. Activity of this enzyme can be attributed to the presence of a glucose phosphotransferase system in the culture [Hickey et al., 1986]. On the other hand, since lactose is not broken down in the upper regions of the small intestine in people lacking the enzyme $\beta$-galactosidase, the presence of this enzyme in the indigenous microbiota can attribute to eliminate lactose intolerance [Charteris et al., 1998].

\section{Surface hydrophobicity}

One of the most important diagnostic ways to detect the attachment of bacteria to host tissue is the hydrophobic nature of the outermost surface of microorganisms [Rosenberg et al., 1980]. Table 1 shows L. plantarum MT.ZH593 (62.54\%) and L. fermentum MT.ZH893 (58.39\%) had the highest CSH percentage through strong hydrophobic interaction, whereas the lowest CSH level belonged to L. casei MT.ZH493 (14.56\%; P<0.05). Based on Colloca et al. [2000], the CSH of lactobacilli strain can be classified into three groups including low hydrophobicity or hydrophilic (0-35\%) (L. plantarum MT.ZH193, L. plantarum MT.ZH293 and L. casei MT.ZH493), moderate hydrophobicity (36-70\%) (L. plantarum MT.ZH393, L. plantarum MT.ZH593, L. pentosus MT.ZH693, L. fermentum MT.ZH893 and L. fermentum MT.ZH993), and high hydrophobicity (71-100\%). In other words, suitable CSH for the selected LABs introduces them as interest probiotic candidates because this fact favors the colonization of mucosal surfaces and plays an important role in adhesion of these bacteria to epithelial cells and extracellular membrane proteins and thus their maintenance in the human gastrointestinal tract [Zsreba et al., 1997].

\section{Susceptibility to antimicrobials}

Table 2 presents the susceptibility of LAB strains isolated from Koozeh cheese against some antibiotic compounds using the disc diffusion method. As considered in this table, all the strains were resistant to vancomycin and streptomycin. Arici et al. [2004] earlier showed also high levels of resistance to 
TABLE 2. Susceptibility of LABs isolated from Koozeh cheese to antibiotics.

\begin{tabular}{|c|c|c|c|c|c|c|c|c|}
\hline \multirow{2}{*}{ Strain } & \multicolumn{8}{|c|}{ Antibiotics ${ }^{\mathrm{a}, \mathrm{b}}$} \\
\hline & V30 & GM10 & $\mathrm{T} 30$ & CRO30 & Ch30 & AMX25 & E15 & $\mathrm{S} 10$ \\
\hline L. plantarum MT.ZH193 & $\mathrm{R}$ & MS & MS & MS & S & S & MS & $\mathrm{R}$ \\
\hline L. plantarum MT.ZH293 & $\mathrm{R}$ & $\mathrm{R}$ & $\mathrm{R}$ & MS & S & S & S & $\mathrm{R}$ \\
\hline L. plantarum MT.ZH393 & $\mathrm{R}$ & $\mathrm{R}$ & MS & MS & S & MS & MS & $\mathrm{R}$ \\
\hline L. plantarum MT.ZH593 & $\mathrm{R}$ & $\mathrm{R}$ & $\mathrm{R}$ & MS & S & S & S & $\mathrm{R}$ \\
\hline L. casei MT.ZH493 & $\mathrm{R}$ & S & S & S & S & S & S & $\mathrm{R}$ \\
\hline L. pentosus MT.ZH693 & $\mathrm{R}$ & $\mathrm{R}$ & MS & MS & MS & MS & MS & $\mathrm{R}$ \\
\hline L. fermentum MT.ZH893 & $\mathrm{R}$ & $\mathrm{R}$ & $\mathrm{R}$ & MS & MS & MS & $\mathrm{R}$ & $\mathrm{R}$ \\
\hline L. fermentum MT.ZH993 & $\mathrm{R}$ & $\mathrm{R}$ & $\mathrm{R}$ & $\mathrm{R}$ & $\mathrm{R}$ & $\mathrm{R}$ & $\mathrm{R}$ & $\mathrm{R}$ \\
\hline
\end{tabular}

${ }^{a}$ Antibiotics (Disk potency): V30 = Vancomycin $(30 \mu \mathrm{g}) ;$ GM10 = Gentamycin $(10 \mu \mathrm{g}) ;$ T30 = Tetracycline $(30 \mu \mathrm{g}) ;$ CRO30 = Ceftriaxon $(30 \mu \mathrm{g}) ;$ Ch30 = Chloramphenicol $(30 \mu \mathrm{g}) ;$ AMX25 = Amoxicillin $(25 \mu \mathrm{g}) ;$ E15 = Erythromycin $(15 \mu \mathrm{g}) ; \mathrm{S} 10=$ Streptomycin $(10 \mu \mathrm{g}) .{ }^{\mathrm{b}} \mathrm{R}:$ resistance; MS: moderate susceptibility; S: susceptibility.

TABLE 3. Antimicrobial activity of LABs isolated from Koozeh cheese estimated by spot test method.

\begin{tabular}{l|c|c|c|c|c}
\hline \multirow{2}{*}{ Strain } & \multicolumn{5}{c}{ Pathogen inhibition } \\
\cline { 2 - 6 } & E. coli & S.enterica & E. hirea & S. aureus & Ps. aeruginosa \\
\hline L. plantarum MT.ZH193 & ++ & ++ & ++ & ++ & ++ \\
L. plantarum MT.ZH293 & - & - & ++ & - & ++ \\
L. plantarum MT.ZH393 & ++ & ++ & ++ & ++ & ++ \\
L. plantarum MT.ZH593 & ++ & ++ & ++ & ++ \\
L. casei MT.ZH493 & + & - & + & + & + \\
L. pentosus MT.ZH693 & ++ & ++ & ++ & ++ \\
L. fermentum MT.ZH893 & ++ & ++ & ++ & ++ \\
L. fermentum MT.ZH993 & ++ & ++ & + & ++
\end{tabular}

Activity: $\pm=$ inhibition but no clear halo; $+=$ presence of a clear zone of growth inhibition around spots $>1 \mathrm{~mm} ;++=$ presence of a clearly defined inhibition zone between 2 and $5 \mathrm{~mm}$ surrounding the colony in the spot test; $-=$ no inhibition.

streptomycin for all investigated lactobacilli. Kirtzalidou et al. [2011] showed some Lactobacillus spp. such as L. rhamnosus, L. casei, L. plantarum, L. fermentum, L. brevis and L. curvatus were intrinsically resistant to vancomycin. L. plantarum MT.ZH193 only had a moderate susceptibility to gentamycin, while other the strains were resistant to this antibiotic (Table 2). Resistance to gentamycin as an aminoglycoside antibiotic is considered to be intrinsic in the Lactobacillus genus and is attributed to the absence of cytochrome-mediated electron transport, which mediates drug uptake [MonteagudoMera et al., 2012]. L. fermentum MT.ZH993 was also resistant to ceftriaxon and amoxicillin (Table 2). Therefore, this lactic strain can be beneficial for consumption to patients who are under these antibiotic treatments. All the selected LAB strains had an absolute or moderate susceptibility to chloramphenicol. However, both strains of L. fermentum (MT. ZH893 and MT.ZH993) were resistant toward tetracycline and erythromycin. Moreover, the strains of L. plantarum MT.ZH293 and MT.ZH593 were also resistant to tetracycline (Table 2). Devirgiliis et al. [2011] also reported on the resis- tance of lactobacilli from cheese to erythromycin, tetracycline and chloramphenicol.

\section{Hydrogen peroxide production}

The levels of hydrogen peroxide generated by LAB isolated from Koozeh cheese are given in Table 1. Except for L. plantarum MT.ZH393, all the isolates $(4.41-7.12 \mu \mathrm{g} / \mathrm{mL})$ had a high potential to produce hydrogen peroxide. Similar results were earlier reported in relation to some LAB strains screened from dairy and human origin [Monteagudo-Mera et al., 2012]. The growth of many psychotropic microorganisms and pathogens at refrigeration temperatures and also vaginal colonization by pathogenic species can be prevented using oral administration of different LABs with hydrogen peroxide production potential [Monteagudo-Mera et al., 2012]. It has been demonstrated that some strains of L. acidophilus from dairy origins were able to inhibit Pseudomonas species by producing 1.18 to $1.62 \mathrm{mmol} / \mathrm{L}$ of hydrogen peroxide in agitated cultures [Collins \& Aramaki, 1980]. Moreover, foodborne pathogens such as E. coli O157:H7, Salmonella 
enteritidis and Listeria monocytogenes were efficiently killed by the hydrogen peroxide-producing LABs [Venkitanarayanan et al., 2002].

\section{Antagonistic activity against pathogens}

Table 3 reveals that all the selected strains except L. plantarum MT.ZH293 and L. pentosus MT.ZH693 inhibited the growth of St. aureus and P. aeruginosa. Our results showed that only L. pentosus MT.ZH693 among the studied lactic isolates cannot inhibit $E$. hirea. Moreover, both isolates of L. plantarum MT.ZH293 and L. casei MT.ZH493 were not able to prevent growth of $S$. enterica. The inhibition of $E$. coli without observing clear halo was found by L. casei MT.ZH493 (Table 3). However, this pathogen was grown in the presence of L. plantarum MT.ZH293. Other strains highly inhibited the activity of $E$. coli (Table 3 ). The inhibitory activity against pathogens is mostly due to the metabolites, such as organic acids, hydrogen peroxide and bacteriocins produced by the probiotic bacteria [Modzelewska-Kapituła et al., 2007; Oh et al., 2003]. Tejero-Sarinena et al. [2012] reported on the antagonistic potential of a number of probiotic lactobacilli strains against human pathogens such as St. aureus, S. typhimurium, E. coli and E. faecalis. In general, the investigated lactic strains had a high therapeutic or prophylactic potential in treatments against infectious diseases.

\section{CONCLUSIONS}

In the present study, in vitro probiotic properties of eight lactobacillus strains isolated from an Iranian traditional cheese "Koozeh" in terms of bile tolerance, tolerance to simulated gastric juice, $\beta$-galactosidase activity, $\mathrm{CSH}$, hydrogen peroxide production, susceptibility to antibiotics and pathogen microorganisms were investigated. Results showed that all the lactic strains were potent probiotics to develop new formulations for designing functional food products with health-promoting properties. According to the analyses, L. fermentum (MT.ZH893 and MT.ZH993) and L. plantarum MT.ZH593 are the best probiotics among the tested ones. More researches are also needed on other potential probiotic characteristics of the selected strains in this study.

\section{RESEARCH FUNDING}

The authors gratefully acknowledge the financial support from the Tarbiat Modares University.

\section{CONFLICT OF INTEREST}

None declared.

\section{REFERENCES}

1. Arici M., Bilgin B., Sagdic O., Ozdemir C., Some characteristics of Lactobacillus isolates from infant faeces. Food Microbiol., 2004, 21, 19-24.

2. Belviso S., Giordano M., Dolci P., Zeppa G., In vitro cholesterollowering activity of Lactobacillus plantarum and Lactobacillus paracasei strains isolated from the Italian Castelmagno PDO cheese. Dairy Sci. Technol., 2009, 89, 169-176.

3. Blanquet S., Zeijdner E., Beyssac E., Meunier J.P., Denis S., Havenaar R., Alric M., A dynamic artificial gastrointestinal system for studying the behavior of orally administered drug dosage forms under various physiological conditions. Pharmaceut. Res., 2004, 21, 585-591.

4. Brashears M.M., Gilliland S.E., Buck L.M., Bile salt deconjugation and cholesterol removal from media by Lactobacillus casei. J. Dairy Sci., 1998, 81, 2103-2110.

5. Charteris W.P., Kelly P.M., Morelli L., Collins J.K., Ingredient selection criteria for probiotic microorganisms in functional dairy foods. Int. J. Dairy Technol., 1998, 51, 123-136.

6. Collins E.B., Aramaki K., Production of hydrogen peroxide by Lactobacillus acidophilus. J. Dairy Sci., 1980, 63, 353-357.

7. Colloca M., Ahumada M., Lopez M., Nader-Macas M., Surface properties of lactobacilli isolated from healthy Subjects. Oral. Dis., 2000, 6, 227-233.

8. Devirgiliis C., Barile S., Perozzi, G., Antibiotic resistance determinants in the interplay between food and gut microbiota. Gen. Nutr., 2011, SI, 6, 275-284.

9. dos Santos K.M.O., Vieira A.D.S., Buriti F.C.A., do Nascimento J.C.F., de Melo M.E.S., Bruno L.M., Borges M.D.F., Rocha C.R.C., Lopes A.C.D.S., Franco B.D.G.D.M., Todorov S.D., Artisanal Coalho cheeses as source of beneficial Lactobacillus plantarum and Lactobacillus rhamnosus strains. Dairy Sci. Technol., 2015, 95, 209-230.

10. El-Shafei K., Abd El-Gawad M.A.M., Dabiza N., Sharaf O.M., Effat B.A., A mixed culture of Propionibacterium thoenii P-127, Lactobacillus rhamnosus and Lactobacillus plantarum as protective cultures in Kareish cheese. Pol. J. Food Nutr. Sci., 2008, 58, 433-441.

11. Ferrando V., Quiberoni A., Reinhemer J., Suárez V., Resistance of functional Lactobacillus plantarum strains against food stress conditions. Food Microbiol., 2015, 48, 63-71.

12. Gardiner G.E., Casey P.G., Casey G., Lynch P.B., Lawlor P.G., Hill C., Fitzgerald G.F., Stanton C., Ross R.P., Relative ability of orally administered Lactobacillus murinus to predominate and persist in the porcine gastrointestinal tract. Appl. Environ. Microbiol., 2004, 70, 1895-1906.

13. Hickey M.W., Hillier A.J., Jago G.R., Transport and metabolism of lactose, glucose, and galactose in homofermentative Lactobacilli. Appl. Environ. Microbiol., 1986, 51, 825-831.

14. Jayne-Williams D.J., The application of miniaturized methods for characterisation of various organisms isolated from the animal gut. J. Appl. Bacteriol., 1976, 40, 189-200.

15. Kirmaci A.H., Effect of wild strains used as starter cultures on free fatty acid profile of Urfa cheese. Pol. J. Food Nutr. Sci., 2016, 66, 302-310.

16. Kirtzalidou E., Pramateftaki P., Kotsou M., Kyriacou A., Screening for lactobacilli with probiotic properties in the infant gut microbiota. Anaerobe, 2011, 17, SI, 440-443.

17. Leite A.M.O., Miguel M.A.L., Peixoto R.S., Ruas-Madiedo P., Paschoalin V.M.F., Mayo B., Delgado S., Probiotic potential of selected lactic acid bacteria strains isolated from Brazilian kefir grains. J. Dairy Sci., 2015, 98, 3622-3632.

18. Libudzisz Z., Probiotics in human nutrition - Plenary lecture. Pol. J. Food Nutr. Sci., 2006, 56, 47-53. 
19. Makinen K., Berger B., Bel-Rhlid R., Ananta E., Science and technology for the mastership of probiotic applications in food products. J. Biotechnol., 2012, 162, 356-365.

20. Mathara J.M., Schillinger U., Kutima P.M., Mbugua S.K., Guigas C., Franz C., Holzapfel W.H., Functional properties of Lactobacillus plantarum strains isolated from Maasai traditional fermented milk products in Kenya. Curr. Microbiol., 2008, 56, 315-321.

21. Modzelewska-Kapituła M., Kłębukowska L., Kornacki K., Influence of inulin and potentially probiotic Lactobacillus plantarum strain on microbiological quality and sensory properties of soft cheese. Pol. J. Food Nutr. Sci., 2007, 57, 143-146.

22. Monteagudo-Mera A., Rodríguez-Aparicio L., Rúa J., Martínez-Blanco H., Navasa N., García-Armesto M.R., Ferrero M.A., In vitro evaluation of physiological probiotic properties of different lactic acid bacteria strains of dairy and human origin. J. Funct. Food, 2012 4, 531-541.

23. Moser S.A., Savage D.C., Bile salt hydrolase activity and resistance to toxicity of conjugated bile salts are unrelated properties in lactobacilli. Appl. Environ. Microbiol., 2001, 67, 3476-3480.

24. Oh S.J., Kim M.H., Churey J.J., Worobo R.W., Purification and characterization of an antilisterial bacteriocin produced by Leuconostoc sp. W65. J. Microbiol. Biotechnol., 2003, 13, 680-686

25. Özer B., Uzun Y.S., Kirmaci H.A., Effect of microencapsulation on viability of Lactobacillus acidophilus LA-5 and Bifidobacterium bifidum BB-12 during Kasar cheese ripening. Int. J. Dairy Technol., 2008, 61, 237-244.

26. Pennacchia C., Ercolini D., Blaiotta G., Pepe O., Mauriello G., Villani F., Selection of Lactobacillus strains from fermented sausages for their potential use as probiotics. Meat Sci., 2004, 67, 309-317.

27. Pinto M.G.V., Franz C.M.A.P., Schillinger U., Holzapfel W., Lactobacillus spp. with in vitro probiotic properties from human faeces and traditional fermented products. Int. J. Food Microbiol., 2006, 109, 205-214.

28. Prasad J., Gill H., Smart J., Gopal P.K., Selection and characterization of Lactobacillus and Bifidobacterium strains for use as probiotics. Int. Dairy J., 1998, 8, 993-1002.

29. Ripamonti B., Agazzi A., Bersani C., De Dea P., Pecorini C., Pirani S., Rebucci R., Savoini G., Stella S., Stenico A., Tirloni E., Domeneghini C., Screening of species-specific lactic acid bacteria for veal calves multi-strain probiotic adjuncts. Anaerobe, 2011, 17, 97-105.

30. Rosenberg M., Gutnick D., Rosenberg E., Adherence of bacteria to hydrocarbons: a simple method for measuring cell surface hydrophobicity. FEMS Microbiol. Lett., 1980, 9, 29-33.

31. Saad N., Delattre C., Urdaci M., Schmitter J., Bressollier P., An overview of the last advances in probiotic and prebiotic field. LWT-Food Sci. Technol., 2013, 50, 1-16.

32. Salari M., Razavi S.H., Gharibzahedi S.M.T., Characterising the synbiotic beverages based on barley and malt flours ferment- ed by Lactobacillus delbrueckii and paracasei strains. Qual. Assur. Saf. Crop. Food, 2015, 7, 355-361.

33. Shah N.P., Functional cultures and health benefits. Int. Dairy J., 2007, 17, 1262-1277.

34. Sharma P., Tomar S.K., Goswami P., Sangwan V., Singh R., Antibiotic resistance among commercially available probiotics. Food Res. Int., 2014, 57, 176-195.

35. Sharpe M.E., Fryer T.F., Smith D.G., Identification of the Lactic Acid Bacteria. 1979, in: Identification Methods for Microbiologists (eds. E.M. Gibbs, F.A. Skinner). London Academic Press, pp. 233-259.

36. Shokoohi M., Razavi S.H., Labbafi M., Vahidinia A., Gharibzahedi S.M.T., Wheat sprout flour as an attractive substrate for the producing probiotic fermented beverages: Process development and product characterization. Qual. Assur. Saf. Crop. Food, 2015, 7, 469-475.

37. Tejero-Sarinena S., Barlow J., Costabile A., Gibson G.R., Rowland I., In vitro evaluation of the antimicrobial activity of a range of probiotics against pathogens: evidence for the effects of organic acids. Anaerobe, 2012, 18, 530-538.

38. Torkamani M.G., Razavi S.H., Gharibzahedi S.M.T., Critical quality attributes of Iranian 'Taftoon' breads as affected by the addition of rice bran sourdough with different lactobacilli. Qual. Assur. Saf. Crop. Food, 2015, 7, 305-311.

39. Venkitanarayanan K.S., Lin C.M., Bailey H., Doyle M.P., Inactivation of Escherichia coli O157:H7, Salmonella enteritidis and Listeria monocytogenes on apples, oranges, and tomatoes by lactic acid with hydrogen peroxide. J. Food Protect., 2002, 65, 100-105.

40. Villegas E., Gilliland S.E., Hydrogen peroxide production by Lactobacillus delbrueckii subsp lactis at $5^{\circ} \mathrm{C}$. J. Food Sci., 1998, 63, 1070-1074.

41. Vinderola C.G., Reinheimer J.A., Lactic acid starter and probiotic bacteria, a comparative "in vitro" study of probiotic characteristics and biological barrier resistance. Food Res. Int., 2003, 36, 895-904.

42. Vinderola G., Capellini B., Villareal F., Suárez V., Quiberoni A., Reinheimer J., Usefulness of a set of simple in vitro tests for the screening and identification of probiotic candidate strains for dairy use. LWT-Food Sci. Technol., 2008, 41, 1678-1688.

43. Xanthopoulos V., Litopoulou-Tzanetaki E., Tzanetakis N., Characterization of Lactobacillus isolates from infant faeces as dietary adjuncts. Food Microbiol., 2000, 17, 205-215.

44. Zago M., Fornasari M.E., Carminati D., Burns P., Suàrez V., Vinderola G., Reinheimer J., Giraffa G., Characterization and probiotic potential of Lactobacillus plantarum strains isolated from cheeses. Food Microbiol., 2011, 28, 1033-1040.

45. Zareba T.W., Pascu C., Hryniewicz W., Waldstrom T., Binding of extracellular matrix proteins by Enterococci. Curr. Microbiol., 1997, 34, 6-11.

Submitted: 28 October 2015. Revised: 7 January and 28 January 2016. Accepted: 15 February 2016. Published on-line: 5 October 2016. 